\title{
Recobrimento de goiabas com filmes proteicos e de quitosana
}

\author{
Thales Sandoval Cerqueira $\left({ }^{* *}\right)$; Angelo Pedro Jacomino ( $\left.{ }^{1}\right)$; Fabiana Fumi Sasaki ( $\left.{ }^{1}\right)$; \\ Ana Cláudia Carraro Alleoni (') \\ (') Laboratório de Pós-colheita de produtos hortícolas. Escola Superior de Agricultura "Luiz de Queiroz", Caixa Postal 9, 13418- \\ 900 Piracicaba (SP).E-mail: thalesscerqueira@yahoo.com.br (*) Autor correspondente. Bolsista FAPESP. jacomino@esalq.usp.br; \\ fsasaki@esalq.usp.br; ana.claudia.carraro@terra.com.br
}

Recebido: 24/jun./2009; Aceito: 18/mai./2010

\section{Resumo}

Este trabalho teve como objetivo determinar o efeito de recobrimentos proteicos e de quitosana na conservação de goiabas 'Kumagai'. Utilizaram-se recobrimentos de quitosana com e sem glicerol (1:1) nas concentrações de 2\%, 4\% e 6\%, concentrado proteico de soro de leite (CPSL) com glicerol (1:1) nas concentrações de 6\% e 8\% e glúten com glicerol (1:1) a 10\% e $12 \%$. Os recobrimentos foram aplicados por imersão das goiabas nas soluções por 10 segundos e posterior à secagem em temperatura ambiente com ventilação forçada. Em seguida as frutas foram armazenadas em condição ambiente $\left(22 \pm 2{ }^{\circ} \mathrm{C}\right.$ e $70 \pm 5 \%$ UR) durante oito dias. O tratamento com quitosana $6 \%$ sem glicerol impediu o amadurecimento das frutas, odor alcoólico no oitavo dia. Com exceção do tratamento com quitosana a 6\%, nos tratamentos os efeitos foram semelhantes e não alteraram o tempo de conservação das goiabas.

Palavras-chave: Psidium guajava, pós-colheita, coberturas comestíveis, polissacarídeos, glúten, soro de leite.

\section{Protein and chitosan coatings on guavas}

\section{Abstract}

The objective of this study was to evaluate the effects of chitosan and protein coatings on the conservation of 'Kumagai' guavas. Chitosan coatings with and without glycerol (1:1) at 2; 4 and 6\% concentrations, whey protein concentrate (WPC) coatings with glycerol (1:1) at 6 and $8 \%$ concentrations and gluten with glycerol coatings (1:1) at 10 and $12 \%$ concentrations were used. Coatings were applied by dipping guavas in the solutions for 10 seconds and dried at room temperature in a forced air circulation chamber. Subsequently, fruit were stored at room temperature $\left(22 \pm 2{ }^{\circ} \mathrm{C}\right.$ and $\left.70 \pm 5 \% \mathrm{RH}\right)$ for 8 days. Chitosan coating at $6 \%$ without glycerol prevented fruit ripening and fruit gave off an alcoholic smell on the $8^{\text {th }}$ day. Apart from the chitosan coating at 6\%, the other treatments caused similar responses when compared to control group within the fruit conservation period considered.

Key words: Psidium guajava, postharvest, edible coating, polysaccharides, gluten, whey protein concentrate.

\section{INTRODUÇÃO}

A cultura da goiabeira (Psidium guajava L.) é importante no contexto da fruticultura brasileira. O Brasil produz aproximadamente 400 mil toneladas, sendo os Estados de Sáo Paulo e Pernambuco seus principais produtores (IвGE, 2008).

Os processos fisiológicos de deterioração dos frutos são acelerados e seus efeitos podem ser agravados pelas condiçôes às quais são submetidos após a colheita. $\mathrm{O}$ uso de tecnologias de conservação pós-colheita é imprescindível para aumentar o período de comercialização.

Os recobrimentos comestíveis podem melhorar o marketing do alimento, com relação à qualidade nutricional, segurança, e aumento no tempo de conservação, pois têm funçôes como: retardar a perda de umidade, retardar as trocas gasosas, aumentar a integridade estrutural, provendo alguma proteção física contra injúrias, reter componentes voláteis, constituintes do odor e do sabor e atuar como veículo de aditivos alimentícios, como, por exemplo, agentes antimicrobianos (Krochta e De Mulder-johnston, i 997; Reinoso et al., 2008).

As coberturas proteicas à base de soro de leite $\mathrm{e}$ glúten são biodegradáveis, transparentes, mecanicamente fortes e com relativa resistência à água. Estas coberturas conferem proteção mecânica à fruta, o que contribui para minimizar as injúrias, além de ser excelente barreira para $\mathrm{O}_{2}$ e $\mathrm{CO}_{2}$, e boa opção para recobrir frutas frescas (GuILBERT et al., 2002). 
Quitosana é um aminopolissacarídeo obtido da desacetilação da quitina sendo um dos mais abundantes polímeros naturais nos organismos vivos tais como crustáceos, insetos e fungos. É uma fibra animal, que tem sido comprovada como não tóxica e biodegradável (GuerraSANCHÉZ et al., 2009).

A quitosana pode ajudar no controle do aparecimento de doenças pós-colheita, pois exerce dupla função, interferindo diretamente no crescimento do patógeno e ativando várias respostas de defesa no tecido vegetal (AgrawaL et al., 2002; Guerra-SANCHÉZ et al., 2009).

O glicerol é um plastificante que reduz as pontes de hidrogênio, ampliando os espaços intermoleculares, aumentando a flexibilidade e a permeabilidade do filme. Plastificantes, são substâncias que alteram as propriedades físicas e mecânicas dos filmes (BANKer, 1966).

O presente trabalho teve como objetivo determinar o efeito de recobrimentos comestíveis de proteínas e de quitosana na conservação de goiabas 'Kumagai' armazenadas à temperatura ambiente.

\section{MATERIAL E MÉTODOS}

Foram utilizadas goiabas da variedade Kumagai provenientes de pomares comerciais do município de Campinas. Os lotes de frutas de tamanho uniforme, sem defeitos, colhidas quando a cor da casca começa mudar de verdeescuro para verde-claro e com valores próximos de $117^{\circ}$ para o ângulo de cor e $85 \mathrm{~N}$ para firmeza, baseando-se nos índices determinados por Cavalini et al. (2006) para a caracterização do estádio de maturação. Os experimentos foram iniciados em 15/7/2005. As goiabas foram higienizadas em solução de hipoclorito de sódio a 200 ppm de cloro ativo. Em seguida foram submetidas aos vários tratamentos com recobrimentos. Sendo imersas, uma a uma, manualmente em recipientes contendo as soluçóes filmogênicas, durante 10 segundos e colocadas para secar em câmara com circulação forçada de ar. Em seguida, permaneceram armazenadas a $22 \pm 2{ }^{\circ} \mathrm{C}$ e UR de $70 \pm 2 \%$ durante oito dias.

Utilizaram-se soluçôes de quitosana (Cyrbe Química Ltda.) nas concentraçôes de $2 \%, 4 \%, 6 \%$ sem o plastificante glicerol (Synth) e quitosana nas concentraçôes de $2,4 \%, 6 \%$ com o plastificante glicerol na proporção de 1:1 (polissacarídeo:plastificante); concentrado proteico de soro de leite CPSL (Calpro; $75 \%-80 \%$ de proteína) nas concentrações de $6 \%$ e $8 \%$, com glicerol 1:1 (proteína:plastificante) da solução e glúten (Viten/ vital-wheat glúten; 85\%-90\% de proteína) nas concentraçôes proteicas de 10\% e 12\%, com glicerol 1:1 (proteína:plastificante).

A quitosana foi pesada juntamente com o ácido cítrico, dissolvida em água destilada (massa/massa) e homogeneizada em agitador magnético por 120 minutos, até a completa dissolução. $\mathrm{O}$ glicerol foi adicionado após a dissolução da quitosana.

O concentrado proteico de soro de leite foi pesado e dissolvido em água destilada, sendo em seguida adicionado o glicerol. A solução foi homogeneizada até a completa dissolução e aquecida em banho-maria a $90{ }^{\circ} \mathrm{C}$ por 30 minutos. Em seguida, foi resfriada até atingir temperatura de $25^{\circ} \mathrm{C}$ e o pH ajustado para 7,0, com $\mathrm{NaOH}$.

O preparo das soluçóes proteicas de glúten seguiu a metodologia de Gennadios et al. (I993), com algumas modificaçôes. O glúten foi dissolvido em $65 \mathrm{~mL}$ de etanol $95 \%$ e $35 \mathrm{~mL}$ de água destilada e em seguida foi acrescentado o glicerol. A solução foi agitada com agitador magnético, sendo feita a correção do $\mathrm{pH}$ para 10,0, com $\mathrm{NaOH}$. A solução foi aquecida por 10 minutos a $75^{\circ} \mathrm{C}$, centrifugada a $2000 \mathrm{rpm}$ a $5^{\circ} \mathrm{C}$ por 10 minutos e aplicada nas frutas.

As frutas com e sem revestimentos foram analisadas de acordo com as metodologias descritas a seguir: a) a perda de massa foi calculada pela diferença entre a massa inicial e a final, medidas em balança semianalítica, com os resultados expressos em porcentagem; b) a coloração da casca foi determinada com colorímetro Minolta, modelo CR-300, tomando-se 2 leituras por fruta, em lados opostos da região equatorial e os resultados foram expressos em ângulo de cor (ho) (Mcguirre, 1992); c) o teor de sólidos solúveis (SS), foi determinado por leitura direta em refratômetro marca Atago, modelo Pallete -101, sendo os resultados expressos em ${ }^{\circ}$ Brix; d) a acidez titulável (AT) foi determinada de acordo com metodologia descrita por Carvalho et al. (1990) e os resultados foram expressos em \% de ácido cítrico na polpa; e) a firmeza da polpa foi determinada empregando-se penetrômetro digital, com ponteira de $8 \mathrm{~mm}$, após a retirada da casca, tomando-se duas leituras por fruta na região equatorial e os resultados foram expressos em Newton; f) o teor de ácido ascórbico foi quantificado por titulometria, de acordo com metodologia descrita por Carvalho et al. (1990), e os resultados foram expressos em mg de ácido ascórbico por 100 $\mathrm{g}$ de polpa; g) a incidência de podridão foi avaliada visualmente contando-se o número de goiabas com presença de podridão. Caracterizaram-se como podridão as lesôes com diâmetro superior a $0,5 \mathrm{~cm}$. Os resultados dessa análise foram expressos em porcentagem de goiabas com podridão.

Para as variáveis perda de massa fresca e cor da casca, as determinaçốes foram executadas a cada 2 dias durante os 8 dias de armazenamento. No caso das variáveis SS, AT, firmeza da polpa, teor de ácido ascórbico e incidência de podridão realizou-se uma determinação para caracterização do lote (dia 0) e no último dia (dia 8).

O delineamento empregado foi o inteiramente casualizado em esquema fatorial 11 × 2 ou 11 × 8 (11 tratamentos e 2 ou 8 dias para análise), dependendo da variável. Cada tratamento foi composto de cinco repetições de três 
goiabas. Os dados foram submetidos à análise de variância (teste F), e as médias comparadas pelo teste de Tukey a $5 \%$ de probabilidade.

\section{RESULTADOS E DISCUSSÃO}

A perda de massa fresca variou durante os oito dias de armazenamento entre $5,7 \%$ e $8 \%$, sendo no controle a maior perda, e o tratamento com quitosana $6 \%$ sem glicerol a menor, diferindo significativamente $(\mathrm{p}>0,05)$ dos demais tratamentos (Tabela 1). Embora se tenha observado diferenças estatísticas entre os tratamentos para a variável perda de massa, visualmente, essas diferenças não são relevantes. Recobrimentos de polissacarídeos e recobrimentos proteicos, devido à sua natureza hidrofílica, constituem barreiras pouco efetivas à troca de água (Kester e Fennema, 1988). Portanto, era esperado que os recobrimentos tivessem pouca interferência nesta variável. SANTos et al. (2008) avaliando pêssegos 'Douradão' recobertos com quitosana $1 \%$, verificaram que esta não reduziu a perda de massa fresca, ocorrendo as maiores perdas mesmo quando comparado ao controle. Segundo Banks et al., (1993) a perda de massa fresca deve ser estudada em conjunto com outras características para a avaliação do processo de amadurecimento, pois a barreira à saída de água também pode impedir a troca de gases, bloqueando com isso o processo de amadurecimento e conduzindo à anaerobiose das frutas.

As goiabas tiveram valores para coloração da casca entre $h^{\circ} 102^{\circ} \mathrm{e} \mathrm{h}^{\circ} 95^{\circ}$ no fim de oito dias de armazenamento. Estes valores demonstram que as frutas após oito dias, ficaram completamente amarelecidas, sendo observado principalmente pelo valor do hue na região do amarelo. Não houve diferença $(p>0,05)$ entre a maioria dos tratamentos, com exceção para o tratamento quitosana $6 \%$ sem glicerol, que manteve as goiabas verdes com ho $114,64^{\circ}$ (Tabela 2). As modificaçōes na coloração das frutas com o amadurecimento são devidas a processos degradativos como, por exemplo, a degradaçáo da clorofila ou de síntese, por exemplo, de carotenóides, sendo um dos principais critérios de julgamento do seu estado de maturação e também do amadurecimento de hortaliças. É provável que a modificação da atmosfera promovida pelo recobrimento quitosana $6 \%$ sem glicerol tenha influenciado na degradação da clorofila, mantendo essas frutas mais verdes que os demais tratamentos.

Tabela 1. Perda de massa fresca (\%) de goiabas recobertas, ou não, com diferentes filmes e armazenadas a $22 \pm 2{ }^{\circ} \mathrm{C}$ e $70 \pm 5 \%$ UR durante 8 dias

\begin{tabular}{|c|c|c|c|c|}
\hline \multirow{2}{*}{ Tratamentos } & \multicolumn{4}{|c|}{ Tempo de armazenamento (dias) } \\
\hline & 2 & 4 & 6 & 8 \\
\hline Quitosana 2\% & $1,85 a b$ & $3,87 \mathrm{abc}$ & $6,06 a b$ & $7,34 a b$ \\
\hline Quitosana 4\% & $1,81 \mathrm{ab}$ & 3,66 bc & $5,60 \mathrm{~b}$ & $6,72 b$ \\
\hline Quitosana 6\% & $1,39 \mathrm{~b}$ & $3,03 \mathrm{c}$ & $4,66 \mathrm{c}$ & $5,67 c$ \\
\hline Quitosana+Glicerol 2\% & $1,98 a b$ & $3,94 \mathrm{ab}$ & $5,89 \mathrm{~b}$ & $6,94 \mathrm{~b}$ \\
\hline Quitosana + Glicerol 4\% & $2,11 a b$ & $4,17 \mathrm{ab}$ & $6,23 a b$ & $7,41 \mathrm{ab}$ \\
\hline Quitosana + Glicerol 6\% & $2,04 \mathrm{ab}$ & $4,03 a b$ & $5,92 \mathrm{~b}$ & $7,10 \mathrm{~b}$ \\
\hline Concentrado Proteico de Soro de Leite + Glicerol 6\% & $2,23 a b$ & $4,20 \mathrm{ab}$ & $6,18 a b$ & $7,29 a b$ \\
\hline Concentrado Proteico de Soro de Leite + Glicerol 8\% & $2,06 a b$ & $3,96 \mathrm{ab}$ & $5,91 \mathrm{~b}$ & $7,03 \mathrm{~b}$ \\
\hline Glúten + Glicerol 10\% & $2,10 a b$ & $4,01 \mathrm{ab}$ & $6,01 \mathrm{ab}$ & $7,19 a b$ \\
\hline Glúten + Glicerol 12\% & $2,25 a b$ & $4,24 \mathrm{ab}$ & $6,27 a b$ & $7,49 a b$ \\
\hline Controle & $2,42 \mathrm{a}$ & $4,60 \mathrm{a}$ & $6,83 \mathrm{a}$ & $8,00 \mathrm{a}$ \\
\hline
\end{tabular}

Médias seguidas de mesma letra minúscula na coluna náo diferem entre si, pelo teste de Tukey a $5 \%$ de probabilidade. C.V.: 11,58\%. No dia zero o valor é igual a $0 \%$.

Tabela 2. Cor da casca $\left(\mathrm{h}^{\circ}\right)$ de goiabas tratadas recobertas, ou não, com diferentes filmes e armazenadas a $22 \pm 2{ }^{\circ} \mathrm{C}$ e $70 \pm 5 \% \mathrm{UR}$ durante 8 dias

\begin{tabular}{lcccc} 
Tratamentos & \multicolumn{4}{c}{ Tempo de armazenamento (dias) } \\
\cline { 2 - 5 } & $\mathbf{2}$ & $\mathbf{4}$ & $\mathbf{6}$ & $\mathbf{8}$ \\
\hline Quitosana 2\% & $114,9 \mathrm{a}$ & $110,04 \mathrm{ab}$ & $104,3 \mathrm{bc}$ & $96,6 \mathrm{bc}$ \\
\hline Quitosana 4\% & $114,18 \mathrm{a}$ & $108,82 \mathrm{~b}$ & $103,88 \mathrm{bc}$ & $95,88 \mathrm{c}$ \\
\hline Quitosana 6\% & $116,22 \mathrm{a}$ & $115,62 \mathrm{a}$ & $115,98 \mathrm{a}$ & $114,64 \mathrm{a}$ \\
\hline Quitosana+Glicerol 2\% & $114,06 \mathrm{a}$ & $109,78 \mathrm{ab}$ & $103,9 \mathrm{bc}$ & $96,5 \mathrm{bc}$ \\
\hline Quitosana + Glicerol 4\% & $112,84 \mathrm{a}$ & $106,84 \mathrm{~b}$ & $100,2 \mathrm{c}$ & $95,08 \mathrm{c}$ \\
\hline Quitosana + Glicerol 6\% & $114,34 \mathrm{a}$ & $108,44 \mathrm{~b}$ & $105,38 \mathrm{bc}$ & $102,34 \mathrm{~b}$ \\
\hline Concentrado Proteico de Soro de Leite + Glicerol 6\% & $114,1 \mathrm{a}$ & $109,0 \mathrm{~b}$ & $101,3 \mathrm{bc}$ & $95,14 \mathrm{c}$ \\
\hline Concentrado Proteico de Soro de Leite + Glicerol 8\% & $114,54 \mathrm{a}$ & $108,66 \mathrm{~b}$ & $101,21 \mathrm{bc}$ & $96,08 \mathrm{bc}$ \\
\hline Glúten + Glicerol 10\% & $114,08 \mathrm{a}$ & $107,1 \mathrm{~b}$ & $101,88 \mathrm{bc}$ & $97,88 \mathrm{bc}$ \\
\hline Glúten + Glicerol 12\% & $113,46 \mathrm{a}$ & $107,36 \mathrm{~b}$ & $103,96 \mathrm{bc}$ & $101,2 \mathrm{bc}$ \\
\hline Controle & $113,94 \mathrm{a}$ & $110,82 \mathrm{ab}$ & $107,04 \mathrm{~b}$ & $99,74 \mathrm{bc}$ \\
\hline
\end{tabular}

Médias seguidas de mesma letra minúscula na coluna não diferem entre si, pelo teste de Tukey a $5 \%$ de probabilidade. C.V.: 2,58\%. No dia zero foi determinado valor igual a 116,82 . 
Modificaçóes na atmosfera podem afetar a atividade respiratória podendo causar anaerobiose, o que resulta na produçáo de maiores quantidades de acetaldeído e etanol. Alto nível de $\mathrm{CO}_{2}$ diminui a atividade de enzimas do processo respiratório e pode inibir a ação do etileno. Recobrimentos podem diminuir a permeabilidade da casca, modificar a atmosfera interna e diminuir a taxa respiratória (BAI et al., 2003). Desta forma, provavelmente, a modificação da composição gasosa afetou diretamente os processos responsáveis pela degradaçáo da clorofila.

O teor de sólidos solúveis não foi influenciado pelos recobrimentos $(p>0,05)$, na avaliação realizada no fim do armazenamento, os quais variaram de 8,2 a $9,2{ }^{\circ} \mathrm{Brix}$ (Tabela 3). Embora a goiaba seja uma espécie que praticamente não armazena amido, pequenos incrementos no teor de sólidos solúveis (SS) têm sido observados durante o amadurecimento. Incremento no teor de SS foi observado por Jacomino et al. (2003) e Fakhouri e Grosso (2003) em goiabas, utilizando outros tipos de coberturas. Segundo Chitarra e Chitarra (2005), o teor de açúcares normalmente aumenta com o amadurecimento das frutas por meio de processos biossintéticos ou pela degradação de polissacarídeos.

Para a acidez titulável, verificou-se que no oitavo dia as frutas com recobrimentos não diferiram $(p>0,05)$ das frutas do tratamento controle (Tabela 3). A acidez em produtos hortícolas é atribuída, principalmente, aos ácidos orgânicos que se encontram dissolvidos nos vacúolos das células, tanto na forma livre, como combinados com sais, ésteres, glicosídeos, etc. Em goiabas, o principal responsável pela acidez é o ácido cítrico (Wilson et al., 1982). O aumento da acidez titulável pode ser explicado, em parte, pelo aumento no teor de ácido ascórbico, o qual também foi verificado em todos os tratamentos. BASSETTO (2005) observou aumento na acidez de goiabas 'Pedro Sato' tratadas com 1-metilciclopropeno. Segundo Azzolini (2004), em goiabas colhidas no estádio 2 (cor da casca mudando de verde-escuro para verde-claro) a acidez titulável foi crescente até o quarto dia após a colheita. MerCado-SiLva et al. (I998), trabalhando com goiabas 'Media China', verificou baixa porcentagem de acidez titulável durante os estádios iniciais do amadurecimento seguidos de aumento quando ocorreu a mudança do estádio 2 para o estádio 3. Este comportamento também foi descrito por DHILlon et al. (I987) para frutas com desenvolvimento durante o período chuvoso e na estação do inverno.

O teor de ácido ascórbico aumentou com o amadurecimento em todos os tratamentos (Tabela 3). EL-Buluk et al. (1997) estudando diversas cultivares de goiaba, observou que o teor de ácido ascórbico aumentou lentamente durante os estádios iniciais e significativamente durante o amadurecimento, independentemente da cultivar. JACOMINO et al. (200I), estudando goiabas 'Kumagai' sob atmosfera modificada associada à refrigeração, verificaram aumento no teor de ácido ascórbico das frutas no decorrer do amadurecimento.

A firmeza da polpa das goiabas diminuiu com o armazenamento em todos os tratamentos, indicando perda da integridade estrutural dos tecidos decorrente do amadurecimento, porém, em menor proporção nas frutas recobertas com solução de quitosana $6 \%$ sem glicerol (Tabela 3). No fim de oito dias de armazenamento as goiabas deste tratamento estavam mais firmes que as dos demais ( $p>0,05)$. O tratamento quitosana $6 \%$ sem glicerol parece ter prejudicado a perda normal de firmeza decorrente do amadurecimento da fruta. Provavelmente, ocorreu excessiva restrição às trocas gasosas entre os tecidos da fruta $\mathrm{e}$ a atmosfera. Desta forma, todo o metabolismo da fruta ficou comprometido, levando à redução dos processos de degradaçáo da parede celular bem como da quebra de pectinas, o que manteve o tecido mais firme. JACOMINo et al. (2003), trabalhando com aplicaçấo de ceras de

Tabela 3. Características físico-químicas de goiabas recobertas, ou não, com diferentes filmes após 8 dias de armazenamento a $22 \pm 2{ }^{\circ} \mathrm{C}$ e $70 \pm 5 \% U R$

\begin{tabular}{|c|c|c|c|c|c|}
\hline \multirow[t]{2}{*}{ Tratamentos } & $\begin{array}{l}\text { Sólidos } \\
\text { solúveis }\end{array}$ & $\begin{array}{l}\text { Acidez } \\
\text { titulável }\end{array}$ & $\begin{array}{c}\text { Ácido } \\
\text { ascórbico }\end{array}$ & $\begin{array}{c}\text { Firmeza da } \\
\text { polpa }\end{array}$ & $\begin{array}{l}\text { Frutos com } \\
\text { podridões }\end{array}$ \\
\hline & ${ }^{\circ}$ Brix & g $100 \mathrm{~g}^{-1}$ & $\mathrm{mg} 100 \mathrm{~g}^{-1}$ & $\mathbf{N}$ & $\%$ \\
\hline Quitosana 2\% & $8,68 \mathrm{a}$ & 0,679 a & $155,90 \mathrm{a}$ & $23,15 b$ & 66 \\
\hline Quitosana 4\% & $8,52 \mathrm{a}$ & $0,657 \mathrm{a}$ & 153,97 a & $27,75 b$ & 60 \\
\hline Quitosana 6\% & $8,22 \mathrm{a}$ & $0,638 a$ & $133,95 \mathrm{ab}$ & $56,30 \mathrm{a}$ & 6 \\
\hline Quitosana + Glicerol 2\% & 8,38 a & $0,663 \mathrm{a}$ & $153,96 \mathrm{a}$ & $25,75 \mathrm{~b}$ & 86 \\
\hline Quitosana + Glicerol 4\% & $8,2 \mathrm{a}$ & $0,632 \mathrm{a}$ & $140,82 \mathrm{ab}$ & $21,29 b$ & 73 \\
\hline Quitosana + Glicerol 6\% & 8,58 a & $0,691 \mathrm{a}$ & $138,24 \mathrm{ab}$ & $33,12 \mathrm{~b}$ & 13 \\
\hline Concentrado Proteico de Soro de Leite + Glicerol 6\% & $9,22 \mathrm{a}$ & $0,668 \mathrm{a}$ & $145,15 \mathrm{ab}$ & $24,01 b$ & 73 \\
\hline Concentrado Proteico de Soro de Leite + Glicerol 8\% & 9,0 a & 0,640 a & $134,67 \mathrm{ab}$ & $26,06 \mathrm{~b}$ & 26 \\
\hline Glúten + Glicerol 10\% & $8,72 \mathrm{a}$ & 0,675 a & $121,86 \mathrm{~b}$ & $28,97 \mathrm{~b}$ & 53 \\
\hline Glúten + Glicerol 12\% & 8,98 a & $0,653 \mathrm{a}$ & $136,12 \mathrm{ab}$ & $29,60 \mathrm{~b}$ & 53 \\
\hline Controle & $8,88 \mathrm{a}$ & $0,642 \mathrm{a}$ & $149,15 \mathrm{a}$ & $32,81 \mathrm{~b}$ & 80 \\
\hline C.V.\% & 6,66 & 4,65 & 8,96 & 14,79 & - \\
\hline Dia 0 & 8,22 & 0,583 & 115,17 & 90,13 & 0 \\
\hline
\end{tabular}

Médias seguidas de mesma letra minúscula na coluna năo diferem entre si, pelo teste de Tukey a $5 \%$ de probabilidade. 
carnaúba em goiabas 'Pedro Sato', observaram que goiabas tratadas com cera Meghwax ECF-100 permaneciam mais firmes do que as dos demais tratamentos e também atribuíram este fato à possível restrição às trocas gasosas.

No tratamento com quitosana $6 \%$ sem glicerol foram observados 6,6\% dos frutos com podridóes (Tabela 3). Este tratamento manteve os frutos com a casca verde e a polpa mais firme, do que os demais. A incidência de podridóes variou de $13 \%$ a $86 \%$ para os demais tratamentos no oitavo dia.

Os tratamentos pouco contribuíram para retardar o amadurecimento e para controlar as podridôes. $\mathrm{O}$ recobrimento com $6 \%$ de quitosana sem glicerol foi o único que influenciou significativamente no amadurecimento, porém de forma excessiva o que levou a um prejuízo na qualidade fim, com presença de odor alcoólico ao final do armazenamento, provavelmente devido a processos fermentativos.

Recobrimentos devem proporcionar atraso no amadurecimento, reduzir a perda de massa e as trocas gasosas, porém sem causar bloqueio das reaçóes metabólicas.

De forma geral, todos os recobrimentos conferiram brilho às frutas, sendo intenso nas coberturas com maiores concentraçôes de solutos. Os recobrimentos de quitosana $6 \%$ sem glicerol, bem como os recobrimentos proteicos nas maiores concentraçóes (CPSL 8\% e glúten 12\%) proporcionaram aspecto artificial depreciando a fruta. $\mathrm{O}$ recobrimento com CPSL na concentração de $6 \%$ devido ao brilho melhorou a aparência externa das frutas, mesmo no fim de oito dias de armazenamento.

Todos os recobrimentos tiveram boa aderência às frutas, sem problema de descamação.

\section{AGRADECIMENTOS}

Os autores agradecem à FAPESP (Fundação de Amparo a Pesquisa do Estado de Sáo Paulo) pelo suporte financeiro.

\section{REFERÊNCIAS}

AGRAWAL, G.K.; RAKWAL, R.; TAMOGAMI, S.; YONEKURA, M.; KUBO, A.; SAJI, H. Chitosan activates defense/stress response (s) in the leaves of Oryza sativa seedlings. Plant Physiology and Biochemistry, v.40, p.1061-1069, 2002.

AZZOLINI, M.; JACOMINO, A.P.; BRON, I.U. Índices para avaliar qualidade pós-colheita de goiabas em diferentes estádios de maturação. Pesquisa Agropecuária Brasileira, v.39, p.139-145, 2004.

BAI, J.; VICTORINE, A.; HAGENMAIER, R.D.; MATTHEIS, J.P.; BALDWIN, E.A., 2003. Formulation of zein coatings for apples (Malus domestica Borkh). Postharvest Biology and Technology, v.28, p.259-268, 2003.
BANKS, N.H.; DADZIE, B.K.; CLELAND, J. Reducing gás exchange of fruits with surface coatings, Postharvest Biology and Technology, v.3, p.269-284, 1993.

BANKER, G.S. Films coating theory and practice. Journal of Pharmaceutical Sciences, v.55, p.81-89, 1966.

BASSETTO, E.; JACOMINO, A.P.; PINHEIRO, A.L.; KLUGE, R.A. Delay of ripening of 'Pedro Sato' guava with 1methylcycloproprene, Postharvest Biology and Technology, v.35, p.303-308, 2005.

CARVALHO, C.R.L.; MANTOVANI, D.M.B.; CARVALHO, P.R.N.; MORAES, R.M.M. Análises químicas de alimentos. Campinas: ITAL, 1990. 121p. (Manual Técnico)

CAVALINI, F.C.; JACOMINO, A.P.; LOCHOSKI, M.A.; KLUGE, R.A.; ORTEGA, E.M.M. Maturity indexes for 'Kumagai' and 'Paluma' guavas. Revista Brasileira de Fruticultura, v.28, p.176$179,2006$.

CHITARRA, M.I.F.; CHITARRA, A.B. Pós-colheita de frutas e hortaliças: fisiologia e manuseio. 2 ed. Lavras: UFLA, 2005, 785p.

DHILLON, B. S.; SINGH, S. N.; KUNDAL, G. S.; MINHAS, P. P. S. Studies on the developmental physiology of guava fruit (Psidium guajava L.) II. Biochemical characters. Punjab Horticultural Journal, v.27, p.212-221, 1987.

EL-BULUK, R.E.; BABIKER, E.F.E.; EL-TINAY, A.H. Changes in chemical composition of guava fruits during development and ripening. Food Chemistry, v.59, p.395-399, 1997.

FAKHOURI, F.M.; GROSSO, C. Efeito de coberturas comestíveis na vida útil de goiabas in natura (Psidium guajava L.) mantida sob refrigeração, Brazilian Journal of Food Technology, v.6, p.203-211, 2003.

GENNADIOS, A.; BRANDENBURG, C. L.; WELLER, C. L.; TESTIN, R. F. Effect of $\mathrm{pH}$ on properties of wheat gluten and soy protein isolate films. Journal of Agriculture and Food Chemistry, v.41, p.1835-1839, 1993.

GUERRA-SÁNCHEZ, M.G.; VEGA-PÉREZ, J.; VELÁZQUEZDEL VALLE, M.G.; HERNÁNDEZ-LAUZARDO, A.N. Antifungal activity and release of compounds on Rhizzophus stolonifer (Ehrenb.: Fr.) Vuill. by effect of chitosan with different molecular weights. Pesticide Biochemistry and Physiology, v.93, p.18-22, 2009 .

GUILBERT, S.; GONTARD, N.; MOREL, M.H.; CHALIER, P.; MICARD, V.; REDL, A. Formation and properties of wheat gluten films and coatings. In: GENNADIOS, A. (Ed.) Protein-Based Films and Coatings. Boca Raton: CRC Press, 2002. p.69-121.

INSTITUTO BRASILEIRO DE GEOGRAFIA E ESTATISTICA. Sistema IBGE de recuperação automática. produção agrícola municipal 2004. Disponível em: www.sidra.ibge.gov.br. Acesso em 5 maio 2008.

JACOMINO, A.P.; KLUGE, R.A.; SARANTÓPOULOS, C.I.G.L.; SIGRIST, J.M.M. Evaluation of plastic packages for guava refrigerated preservation. Packaging Technology and Science, v.14, p.11-19, 2001. 
JACOMINO, A.P;; OJEDA, R. M.; KLUGE R. A.; SCARPARE FILHO, J. A. Conservação de goiabas tratadas com emulsões de cera de carnaúba. Revista Brasileira de Fruticultura, v.25, p.401-405, 2003.

KESTER, J.J.; FENNEMA, O.R. Edible films and coatings: A review. Food Technology, v.42, p.47-59, 1988.

KROCHTA, J.M.; DE MULDER-JOHNSTON, C. Edible and biodegradable polymer films: challenges and opportunities. Food Technology, v.51, p.61-74, 1997.

McGUIRRE, R.G. Reporting of objective color measurements, HortScience, v.27, p. 1254-1255, 1992.

MERCADO-SILVA, E.; BAUTISTA, P.B.; GARCIA-VELASCO, M.A. Fruit development, harvest index ripening changes of guavas produced in central Mexico. Postharvest Biology and Technology, v.13, p.143-150, 1998.

REINOSO, E.; MITTAL, G.S.; LIM, L.T. Influence of whey protein composite coatings on plum (Prunus Domestica L.) fruit quality. Food Bioprocess Technology, v.1, p.314-325, 2008.

SANTOS, C.A.A.; CASTRO, J.V.; PICOLI, A.A.; ROLIM, G.S. Uso de quitosana e embalagem plástica na conservação pós-colheita de pêssegos 'Douradáo'. Revista Brasileira de Fruticultura, v.30, p.88-93, 2008.

WILSON,C.W.; SHAW,P.E.; CAMPBELL,C.W. Determination of organic acids and sugars in guava (Psidium guajava L.) cultivars by high-performance liquid chromatography. Journal of Agriculture and Food Chemistry, v. 33, p. 777-780, 1982. 